\title{
The Current Analysis on Logistic Distribution Model Of Chain Project
}

\author{
Wang Ke \\ School of Economic and Management \\ Shenyang Aerospace University \\ Shenyang China
}

\author{
Wang Xuejie \\ School of Economic and Management \\ Shenyang Aerospace University \\ Shenyang China
}

\begin{abstract}
With the rapid development of China's chain retail industry, our retail business structure and management methods is undergoing change, and increasingly focusing on the logistics aspects of the investment and management, which distribution activities in the important work of the retail chain enterprise logistics system First, the choice of distribution mode is directly related to the level of the chain of logistics, but too conservative logistics model will restrict the development of enterprises. So choose what delivery mode of the chain is an important issue. Cut from the distribution chain development status on the logistics chain mode, in-depth to explore chain logistics in the problems and inadequacies, drawing on the parties to literature data, analyze the existing problems of China's chain logistics and solutions, and chain logistics development outlook.
\end{abstract}

Keywords: chain project; distribution mode; distribution program

\section{INTRODUCTION}

Chain management is a modern business model widely used at the moment in many companies of China, which is conducive to gain scale merit for business and achieve intensive operation, but in the mean time, there is still latent crisis in the resource integration and management of our chain enterprises. Currently, out of stock items is a serious problem in the chain enterprises and the average stock-out rate is up to $9.9 \%$; annual losses from chain enterprises due to stock-out reach as much as 83 billion Yuan. The main cause of this situation is that the inadequate development of logistics distribution system is not synchronized with chain enterprise development. In the logistics distribution system, logistics distribution centers take the core position. The lagging distribution function of logistics distribution center is the fundamental factors affecting the development of the chain industry in China.

Thus, the rationalization of logistics distribution in chain enterprises is the core of the logistics distribution strategy of chain management, is to optimize the overall logistics system by adjusting. Quality of completion and service levels of distribution function directly reflects the degree of satisfaction to the demand in chain enterprise logistics system. Through efficient distribution activities, the total cost of logistics in chains can be reduced, and logistics rates and logistics services level will be improved. And the efficiency of logistics is directly related to their ability to take advantage of the single retail store. For the entire chain enterprise, to ensure the maximization of profits, distribution centers achieve the rationalization of logistics subsystem under the condition of ensuring the profits maximization of chain enterprise big system. Modern chain enterprises urgently need to conduct research on improving logistics distribution patterns.

\section{OVERVIEW OF CHAIN ENTERPRISE}

\section{A. Concept of chain enterprise}

Chain management is a form of business organization and management system, which means a number of companies operating similar goods or services, form a consortium in a certain form, divide the work based on specialization and the overall planning, implement the centralized management on the basis of labor, combine the independent business activities into the overall scale operations so as to achieve scale merit. It's a kind of business model.

\section{B. Concept of logistics distribution}

Distribution is a special and comprehensive type of activity in logistics, which is the close integration of trade flow and logistics, including the trade flow activities and logistics activities, also a form of several functional elements in logistics.

Speaking from logistics, distribution includes almost all the functional elements of logistics, which is a microcosm of logistics or the reflection of entire logistics activities in a small range. General distribution integrates handling, packaging, storage, and transports, and completes the target of delivering the goods by the series of events. Special distribution is also supported by processing activities, so it includes broader aspects.

Speaking from trade flow, the difference between distribution and logistics is that logistics is a product of separation of deal and physical distribution while distribution is a product of the unity of deal and physical distribution; distribution itself is a commercial form. Although the specific implementation of distribution can be achieved by separation of deal and physical distribution, increasingly closer integration of trade flow and logistics is an important guarantee for the success of the distribution seen from the distribution trends. 


\section{STATUS ANALYSIS OF CHAIN ENTERPRISE LOGISTICS DISTRIBUTION MODE}

\section{A. Logistics distribution mode}

Current logistics distribution mode is divided into the following three:

1. Self-distribution

Self-distribution means that all aspects of the logistics distribution in chain enterprise are prepared, organized and managed by itself, and to achieve internal and external goods distribution model. Self-distribution is convenient for the coordination of all aspects, can effectively control the whole process of operation of the logistics system, and reduce transaction costs and avoid disclosure of trade secrets. However, due to the high initial investment, it's suitable for large-scale chain enterprises.

\section{Joint Distribution}

The concept of "Joint Distribution" emerged in the 1970s in Japan. In 1977, the circulation response headquarters, Japanese Ministry of Transport defined "joint distribution" in "Outline of collaborative transportation system implementation" as: in the city, for the rationalization of logistics, under the cooperation of a few shippers with regular freight demand, a truck transporter distributes in one transport system. The connotation of joint distribution is to integrate the existing facilities and technical conditions of chain enterprises, establish chain enterprise alliances with the concept of resources sharing, reduce distribution costs through joint distribution, improve distribution efficiency, and enhance the profitability of each chain enterprise.

\section{Third Party Distribution}

The third-party logistics chain means the third party outside the supply-side and demand-side of chain enterprises logistics completes the logistics services.

A third party is independent logistics service provider, and bear some or all of the logistics functions of chain enterprise logistics transaction parties.

Due to the globalization of the supply chain, logistics activities become increasingly complex, logistics costs are increasingly high, and capital intensity is more and more high. Chain enterprises focus resources on the most important business, and transfer its logistics distribution business to a third -party logistics company, which save logistics costs, improve customer service levels and also contribute to the development of third-party logistics.

\section{B. Classification of chain enterprise logistics distribution mode}

1) Direct distribution model of manufacturer or supplier

The distribution model that the manufacturers or suppliers directly send the required goods of retail chain enterprises to the stores or even shelves. Some of our large-scale manufacturing enterprises involve directly into the distribution logistics activities of retail chains. Some producers distribute to retail chains by the self-built distribution center, such as home appliance company Haier others cooperate with third-party logistics enterprises, establish a distribution system on a national scale and distribute to retail stores, such as daily chemicals manufacturer Procter Gamble, Avon.

2) Retail chains self-distribution model
According to various situations of the enterprise's strategic objectives, the network layout, commodity demand, scale of operation and their own strength, retail chains select the appropriate place, fund the establishment of one or more distribution centers, manage the distribution center by the enterprise, and complete the retail stores distribution tasks of the enterprise.

\section{3) Third-party logistics distribution pattern}

Retail chains generally exhibit the logistics distribution features that a variety of goods, small-batch, highfrequency distribution, multi-point distribution, rapid delivery requirements and the support from perfect information systems, making the logistics activities more complicated. Third-party logistics distribution model is a model the distribution business entrusted to a professional third-party logistics enterprise by retain chain enterprises.

\section{4) The joint distribution model}

Joint distribution, also known as collaborative delivery means in order to improve the efficiency of delivery and achieve distribution rationalization, establish distribution cooperation with a complementary function. This mode is based on the principle of mutual benefit, which contributes to the overall rationalization of distribution in logistics industry. Joint distribution model can be divided into horizontal and vertical coordination of joint distribution. Horizontal distribution is to distribute jointly in the form of agreement, alliance or a joint venture among a number of retail chains. Vertical distribution refers to the development in the direction of supply chain integration of chain enterprises, common establishment of distribution center with suppliers (manufacturers, wholesalers, etc.), and integrated construction of supply chain. Joint distribution is launched with unified planning by the core organization (distribution center) and unified schedule, which includes the implementation of logistics tools and other logistics facilities in terms of logistics base and achieve intensive transport of goods through combined shipment in terms of transport.

\section{Status of chain enterprise logistics distribution mode}

The status quo of China's chain management: Chain management is a product of high-speed economic development brought by the modern industrial revolution, and the product of large-scale socialized production. It came into being in the United States, and spread throughout the world in no time because it is unrestricted from countries and regions, cultural traditions, business manner, and the industry; chain management appeared in all places and areas with required conditions. From 2001 to 2005 , the chain industry grew at the soonest. Of which the first four years, the average annual growth rate of China Chain Store hundred enterprises reached $51 \%$, with an annual sales growth of $38 \%$. In the years of rapid development of Chain industry, the government departments explored the chain industry management, the chain enterprises thought deeply and practiced the development model. In the first half of 2006, our chain enterprises continued to show good momentum of development. Sales volume of the first 30 chain enterprises throughout the country in the first half of 2006 amounted to 275.1 billion Yuan, an increase of $25 \%$ over the same period in 2005; total number of stores is 15,563 , which is an increase of $17.1 \%$ over the same period in 2005 . Chain 
management and chain distribution status realized China's transition from long-term single mode operation to the direction of multi-type business, promoted the improvement of the business automation level, but when advanced technologies improve the sales efficiency, such as POS system in reception, bar code and scanning, the distribution support system at backstage becomes unequally matched. The original manual operation still plays a dominant role.

Situation one: urban distribution involves many administrations, and coordination and management are difficult.

Urban distribution management involves the city traffic police, transportation Authority (Department), urban management, planning and other departments as well as numerous industrial and commercial enterprises. Urban distribution management involves a wide range and coordination and management are difficult. Transport authorities pay attention to the protection of the interests of urban distribution companies, trying to better meet the needs and enhance the delivery service of distribution companies, hoping to reduce urban traffic restrictions, and increase urban distribution nodes; the police department often restricts access and stop of delivery vehicles for smooth traffic; during the planning of roads and commercial outlets, department of land, commerce and planning did not fully consider the needs of the distribution; no reserved distribution sites and access channels often lead to the traffic congestion in the process of distribution, so the city inspectors and traffic police restrict the distribution activities to some extent.

Situation two: urban distribution involves complex managing content and too much overlapping management

In accordance with the relevant duties of departments, from different angles of urban distribution, each main body supervises the urban distribution. Traffic police management focuses on vehicle traffic and parking management, transportation management is responsible for the distribution companies and distribution market. In the complete urban distribution activities, the supervision and management of different departments are often involved in; too much involvement of departments results in overlapping functions.

Situation three: urban distribution market management and distribution enterprise management do not get good results.

Now it is quite common of various illegal loading behavior in urban distribution, and removing seats of passenger car in the freight to evade the access policy is a widespread phenomenon; moreover, repeated phenomenon of illegally engaging in cargo operations and units and individual without obtaining the qualifications engaging in the illegal transport of goods, indicate that remediation efforts of government departments are not enough, unfocused, and have no obvious effect.

How to rationalize urban distribution management system?

First, we must establish a coordination mechanism for managing departments.

Urban distribution is not a separate industry, but are decentralized industries including transportation, telecommunications, commercial goods, industrial management and foreign trade departments in charge of their own, and characterized by separation of departments and fragmentation. But modern urban distribution logistics almost covers transportation, storage, handling, processing, sorting, content distribution, recycling, information and other aspects, as the basic elements, closely constitutes a complete logistics supply chain.

During the urban distribution management, mainly coordinate transportation management department, traffic police, planning, industry and commerce, taxation relationship, establish unified urban distribution committee or office to enhance distribution management led by the transportation department, which is mainly in collaboration with the traffic police, fight for more rights of pass management and proposal, and parking management; fight for more rights of market planning and parking planning while in collaboration with planning department and land department; fight for more preferential polices for distribution business while in collaboration with industry and commerce department, and taxation department.

Second, we must change the way of urban distribution logistics management.

Change from the postposition urban distribution management to the preposition of urban distribution management. The original construction of the city's distribution system is based on the existing urban planning, land layout and existing commercial distribution, satisfiability and adaptation of the existing traffic conditions; city distribution system should now be fully considered in the process of urban planning, business branch planning, and transportation planning. Change from control management to the boot management.

Change from the approval of distribution market to permission; change from limiting freight vehicle traffic to a certain extent of unrestricting; change from cracking down the "black car" of logistics distribution to guiding the social vehicles to participate in urban distribution. Through policy guidance, government encourages urban distribution business development, formulate policies of urban distribution development, regulate the market management of distribution business, and create a good environment for the development of logistics distribution. Actively formulate supporting preferential policies, promote the standardization and information of logistics system, promote the standardization of vehicles, and ensure normal operation of logistics information platform in the efficient, unified, orderly environment through information construction.

Thirdly, we should seize the key logistics distribution management problems.

In collaboration with the planning department, reserve distribution land for companies; in collaboration with the financial sector, provide good financing conditions for the distribution companies; in collaboration with department of finance, give priority to investments in infrastructure of logistics distribution industry and high-tech research; in collaboration with metrology department, set unified scientific measurement standards of urban distribution indicators; in collaboration with the traffic police department, plan, manage and supervise the urban freight vehicles, urban delivery vehicle passage and stop. 


\section{CONCLUSION}

The full text elaborated chain logistics enterprise via several aspects, mainly studied the distribution models of chain logistics enterprises, and finally summarized the paper. From this paper, we got that the development of chain enterprises is inseparable from logistics distribution. Reasonable logistics distribution can achieve uniform procurement chain, unified distribution and unified price. The possibility of establishing a high-degree specialized and socialized logistics distribution concerns whether the scale merit can be fully played

Great efforts should be made to solve the problems of recognizing logistics distribution of chain enterprise in future; logistics distribution awareness and attention are two different concepts. Just paying attention is not necessarily the true understanding of logistics distribution, and real attention is followed by the understanding of logistics distribution. At the industry level, consider how to cooperate between enterprises, how to implement the joint distribution and how to build value-added network, but also develop related standards, norms and rules for chain logistics enterprises. The period of development for logistics distribution in China is not long, with a history of two decades, but logistics distribution has a broad space for development in China; the status and role of chain enterprises will gradually be recognized.

\section{REFERENCES}

[1] Tang Xiangdong. Chain enterprise- logistics distribution organization model analysis [J] Commercial Times, 2009

[2] Zhang Ling. Chain business logistics distribution management [J]. Market Weekly, 2009, (12)

[3] Li Xiaochao. Inquiry of China's chain retail enterprise logistics distribution mode selection [J]. Logistics technology, 2007, 5(8)

[4] Yang Tao, Yang Luming. Exploration of the supermarket chain logistics distribution systems [J]. Market Modernization, 2007, (12): 12-19

[5] Zheng Guangcai. Logistics management of Chain business [M], Beijing: Electric Industry Press, 2009:154-166
[6] Bernard Taylor Data, model and decition-making [M] Beijing: China Machine Press, 2008

[7] Gary millar, Ruhul A.www.511unwen.com Sarker, Risk Analysis and Consumer Protection in B2C Transactions, Joumal 